\title{
Pantethine, a derivative of vitamin B5, favorably alters total, LDL and non-HDL cholesterol in low to moderate cardiovascular risk subjects eligible for statin therapy: a triple-blinded placebo and diet-controlled investigation
}

This article was published in the following Dove Press journal:

Vascular Health and Risk Management

27 February 2014

Number of times this article has been viewed

\author{
Malkanthi Evans' \\ John A Rumberger ${ }^{2}$ \\ Isao Azumano 3 \\ Joseph J Napolitano 4 \\ Danielle Citrolo ${ }^{5}$ \\ Toshikazu Kamiya ${ }^{5}$ \\ 'KGK Synergize Inc, London, ON, \\ Canada; ${ }^{2}$ The Princeton Longevity \\ Center, Princeton, NJ, USA; ${ }^{3}$ Daiichi \\ Fine Chemical Co, Ltd, Toyama, Japan; \\ ${ }^{4}$ Independent Consultant, Allentown, \\ PA, USA; ${ }^{5}$ Kyowa Hakko USA, \\ New York, NY, USA
}

\begin{abstract}
High serum concentration of low-density lipoprotein cholesterol (LDL-C) is a major risk factor for coronary heart disease. The efficacy of pantethine treatment on cardiovascular risk markers was investigated in a randomized, triple-blinded, placebo-controlled study, in a low to moderate cardiovascular disease (CVD) risk North American population eligible for statin therapy, using the National Cholesterol Education Program (NCEP) guidelines. A total of 32 subjects were randomized to pantethine $(600 \mathrm{mg} / \mathrm{day}$ from weeks 1 to 8 and $900 \mathrm{mg} /$ day from weeks 9 to16) or placebo. Compared with placebo, the participants on pantethine showed a significant decrease in total cholesterol at 16 weeks $(P=0.040)$ and LDL-C at 8 and 16 weeks ( $P=0.020$ and $P=0.006$, respectively), and decreasing trends in non-high-density lipoprotein cholesterol at week 8 and week $12(P=0.102$ and $P=0.145$, respectively) that reached significance by week $16(P=0.042)$. An $11 \%$ decrease in LDL-C from baseline was seen in participants on pantethine, at weeks $4,8,12$, and 16 , while participants on placebo showed a $3 \%$ increase at week 16. This decrease was significant between groups at weeks $8(P=0.027)$ and $16(P=0.010)$. The homocysteine levels for both groups did not change significantly from baseline to week 16. Coenzyme $\mathrm{Q}_{10}$ significantly increased from baseline to week 4 and remained elevated until week 16, in both the pantethine and placebo groups. After 16 weeks, the participants on placebo did not show significant improvement in any CVD risk end points. This study confirms that pantethine lowers cardiovascular risk markers in low to moderate CVD risk participants eligible for statins according to NCEP guidelines.
\end{abstract}

Keywords: nutritional and metabolic diseases, hypercholesterolemia, pantethine, cardiovascular diseases, dietary supplements, controlled clinical trial

\section{Introduction}

The National Cholesterol Education Program (NCEP) Expert Panel on Detection, Evaluation, and Treatment of High Blood Cholesterol in Adults (Adult Treatment Panel III [ATP-III]) provides evidence-based recommendations on the management of high blood cholesterol and related disorders. ATP-III reports have identified low-density lipoprotein cholesterol (LDL-C) as the primary target of cholesterol-lowering therapy. Many prospective studies have shown that a high serum LDL-C concentration is a major risk factor for coronary heart disease (CHD). ${ }^{1,2}$ On the basis of accumulated evidence from epidemiological studies and randomized control trials, the ATP-III has proposed a treatment algorithm for LDL-C-lowering therapy. According to the ATP-III
Correspondence: Malkanthi Evans KGK Synergize Inc, 255 Queens Avenue, London, ON, N6A 5R8, Canada

Tel + I 5194389374 ext 239

Fax + I $51943883 \mid 4$

Email mevans@kgksynergize.com 
algorithm, persons are categorized into three risk categories: 1) established CHD and CHD risk equivalents; 2) multiple (two or more) risk factors; and 3) zero to one risk factor. CHD risk equivalents include noncoronary forms of clinical atherosclerotic disease, diabetes, and multiple (two or more) CHD risk factors with 10 -year risk for CHD $>20 \%$. All persons with $\mathrm{CHD}$ or $\mathrm{CHD}$ risk equivalents may be considered to be at high risk. ${ }^{3}$

The NCEP ATP-III guidelines for CHD risk stratification incorporate the concept of global risk assessment to determine the intensity and appropriateness of lipidmodifying treatment. According to the NCEP ATP-III, the LDL-C optimal goal for patients is $<100 \mathrm{mg} / \mathrm{dL}$, with ranges near optimal or above optimal of 100-129 mg/dL, borderline high of 130-159 mg/dL, high of 160-189 mg/dL, and very high of $\geq 190 \mathrm{mg} / \mathrm{dL}$. The risk for cardiovascular disease (CVD) increases further when elevated LDL-C is coupled with other risk factors, such as being overweight, low highdensity lipoprotein cholesterol (HDL-C) levels, high triglyceride (TG) levels, lack of exercise, high-sensitivity C-reactive protein (hs-CRP), high fibrinogen, hypertension, etc. ${ }^{4}$

According to the American Heart Association, an estimated one in three Americans have one or more types of CVD, and approximately half of them are estimated to be age 60 or older. ${ }^{5}$ Based on data from the ATP-III, only about a third of treated patients achieve their LDL-C goal, and less than $20 \%$ of those patients maintain their LDL-C goal. Statins are hypolipidemic agents and are used for treating hyperlipidemia and preventing cardiovascular events. ${ }^{6-8}$ The use of statin therapy is increasing, ${ }^{9}$ and its side effects are becoming more evident to clinicians. Intensive-dose statin therapy has been shown to reduce cardiovascular events; ${ }^{10}$ however, prolonged use of statins at high dose may induce muscle and liver damage $\mathrm{e}^{11,12}$ and has been associated with an increased risk of developing diabetes mellitus. ${ }^{10,13-16}$ A clinical trial of diabetic patients receiving intensive statin therapy reported a loss of glycemic control. ${ }^{17}$ A recent study reported that patients with hypercholesterolemia receiving a high dose of atorvastatin developed insulin resistance as well as higher insulin and hemoglobin $\mathrm{A}_{1 \mathrm{c}}$ levels compared with patients receiving low dosage or placebo. ${ }^{18}$ Thus, further investigation for new and alternative hypolipidemic agents, with better tolerability and fewer side effects, is warranted.

Pantethine is a naturally occurring physiological compound synthesized in the body from pantothenic acid (vitamin B5). It is thought that pantethine, in conjunction with the intermediary cysteamine, inhibits acetyl-coenzyme (CoA) carboxylase and 3-hydroxy-3-methyl-glutaryl-CoA (HMG-CoA) reductase, thereby affecting TG synthesis and lipoprotein metabolism. ${ }^{19-21}$ Pantethine increases CoA levels within the cells, ${ }^{22}$ which favorably modifies lipoprotein metabolism. ${ }^{23,24}$ However, the full mechanism of action of pantethine in lowering cholesterol levels is not fully understood. Since homocysteine is believed to contribute to the onset and progression of atherosclerosis ${ }^{25}$ and is involved in the biosynthesis of $\mathrm{CoA},{ }^{26}$ it is possible that pantethine impacts homocysteine.

Several studies report that pantethine is a well-tolerated hypolipidemic agent that may decrease serum total cholesterol (TC), TG, LDL-C, apolipoprotein (Apo) A-I, and Apo-B. ${ }^{27-32}$ A clinical study of diabetic hyperlipidemic patients on dialysis, treated with $900 \mathrm{mg}$ /day of pantethine reported decreases in TC, very-low density lipoprotein cholesterol (VLDL-C), and TG. ${ }^{33}$ Pantethine may be a safe and effective alternative treatment of hyperlipidemia in patients with health issues who are not eligible for statin therapy.

Pantethine is known to be safe and effective ${ }^{33}$ and has been used as a medicine in Japan for over 40 years. In the US, oral pantethine (Pantesin ${ }^{\circledR}$; Daiichi Fine Chemical Co, Ltd, Toyama, Japan) has been available as a nutritional supplement since 1992. In a recent randomized clinical study in a North American population of participants at conventional low to moderate CVD risk, pantethine produced significant and sustained reductions in LDL-C, TC, and Apo-B. ${ }^{34}$ Based on previous studies on the efficacy of pantethine in participants with CVD risk and its record of tolerability, we hypothesized that oral pantethine would improve cholesterol metabolism in North American subjects at low to moderate CVD risk who are eligible for statin therapy according to the NCEP guidelines. More specifically, we hoped to clarify the benefits of the combination of oral pantethine with a Therapeutic Lifestyle Change (TLC) diet for individuals who are candidates for statins, in order to establish a treatment option with less serious adverse events (AEs). ${ }^{4}$

\section{Material and methods Study objectives}

The primary end point in this study was the change in fasting LDL-C levels from baseline over a 16-week supplementation period. Secondary end points included lipoprotein parameters (fasting: TC, HDL-C, TG, VLDL-C, lipoprotein(a), and Apo-B), anthropomorphic measures (weight; waist circumference; and skin folds, using the Yuhasz skin-fold test), ${ }^{35}$ vital signs (heart rate and blood pressure), and laboratory tests for efficacy and safety (complete blood count [CBC] including platelets, hs-CRP, aspartate aminotransferase [AST], alanine transaminase 
[ALT], homocysteine, creatine kinase [CK], and coenzyme $\left.\mathrm{Q}_{10}\left[\mathrm{CoQ}_{10}\right]\right)$.

\section{Study design}

This study was conducted in compliance with the International Conference on Harmonisation Guidance for Good Clinical Practice and according to the guidelines laid down in the Declaration of Helsinki and its amendments. This study was reviewed by Health Canada's Natural Health Products Directorate (Ottawa, ON, Canada), and the Notice of Authorization was received on December 18, 2008. The Institutional Review Board Services (Aurora, ON, Canada) ethics committee approved all procedures in this study involving human subjects on December 22, 2008. All participants provided written informed consent prior to any study activities. This study was a randomized, triple-blinded, placebo-controlled trial with a 4-week diet lead-in followed by a 16-week treatment period. The study was conducted at two sites, KGK Synergize (London, ON, Canada) and SIBR Research (Bradenton, FL, USA).

\section{Participants}

Male and female participants enrolled in the study were recruited at the two research locations. The subjects were screened by physical examination and blood analysis to determine their eligibility, and 32 participants were randomized into the study. The physical examination included height, weight, waist circumference, skin-fold measurement, heart rate, and blood pressure. Fasting blood work included CBC, TC, HDL-C, LDL-C, TG, AST, ALT, glucose, creatinine, CK, and $\mathrm{CoQ}_{10}$. Females were required to have a negative result for the serum human chorionic gonadotropin test for pregnancy.

Subjects were eligible for enrollment if they were $\geq 21$ years of age and had LDL-C levels above the goal for TLC diet changes: low Framingham Risk Score (FRS) $(<10 \%$ per decade) or zero to one nonlipid risk factors, and LDL-C $>160 \mathrm{mg} / \mathrm{dL}$; or moderate FRS $(>10$ but $<20 \%$ per decade) or two or fewer nonlipid risk factors, and an LDL-C $>130 \mathrm{mg} / \mathrm{dL}$. Subjects were excluded if they had a history of gastrointestinal surgery, type I or type II diabetes, blood disorders, concurrent renal and/or liver failure, or significantly abnormal liver function tests; were using statins or other prescription medications to treat hyperlipidemia; had a diet high in soy or other food, supplements or natural products known to reduce cholesterol, or had followed the TLC diet within 12 weeks before the start of the study; were immune-compromised; used oral or injectable systemic corticosteroids, unless on a stable dose for more than 12 weeks; had CVD; had uncontrolled or untreated hypertension, defined as systolic pressure $>160 \mathrm{mmHg}$ or diastolic pressure $>100 \mathrm{mmHg}$; had used prescribed medication or over-the-counter supplements for weight loss within the 12 weeks prior to randomization; had allergy or sensitivity to the investigational product ingredients; or had any other condition that, in the investigator's opinion, adversely affected the subjects' ability to complete the study or its measures, or that posed a significant risk to the subject.

\section{Dietary intervention and diet lead-in}

A registered dietician instructed participants on the TLC diet. The optional addition of 10 to $25 \mathrm{~g}$ /day viscous fibers and/or $2 \mathrm{~g} /$ day plant stanols/sterols and/or soy protein was excluded from the prescribed diet. Participants were required to follow the TLC diet for 4 weeks leading into the study (screening to baseline) so that the effect of the TLC diet on their lipid levels could be evaluated prior to the start of the supplementation. This eliminated potential contributions from varied diets between participants. The participants were required to remain on the TLC diet for the duration of the study and were required to complete a 3-day food record for any 2 weekdays and 1 weekend day before the next visit. To promote compliance with the TLC diet, the food records were completed and returned for review and counsel by the dietician at each study visit. The food records were analyzed for average daily energy intake of protein, fats, carbohydrates, and fiber.

\section{Randomization and blinding}

On completion of the 4-week TLC diet lead-in, participants were randomized in a 1:1 ratio to receive either pantethine or the placebo. A blocking factor of two was used for randomization. To preserve blinding, the investigational tablets and nonactive placebo tablets were identical in appearance and sealed in identical blister packs identifiable only by randomization number.

\section{Investigational product}

The investigational product was the pharmaceutical grade, proprietary product Pantesin HF55. Each tablet contained $300 \mathrm{mg}$ of active ingredient and was manufactured by Eagle Nutritionals (Carlstadt, NJ, USA). The blister packs were manufactured by Generic Pharmaceutical Services (Hauppauge, NY, USA) and were labeled in accordance with the International Conference on Harmonisation Good Clinical Practice guidelines as well as applicable local regulations. Each blister pack contained two active ingredient 
tablets and one placebo tablet $(600 \mathrm{mg} /$ day dose, from weeks 1 to 8$)$, three active ingredient tablets $(900 \mathrm{mg}$ /day dose from weeks 9 to16), or three placebo tablets. The participants in both groups took one tablet three times per day for the entire study period, from baseline to week 16. Compliance was assessed by reviewing the returned blister packs.

\section{Clinical assessments}

Participants returned to the clinic at weeks $0,2,4,8,12$, and 16 and upon each visit, fasting (12 hours) blood was collected for analysis (Gamma-Dynacare Medical Laboratories, London, ON, Canada) of the lipid panel (TC, HDL-C, LDL-C, TG, VLDL-C, Apo-B, and lipoprotein), and markers of safety; CBC, electrolytes, and liver and kidney function tests. TG was analyzed by an enzymatic colorimetric assay performed on a Roche P800 Clinical Chemistry Analyzer, VLDL-C was calculated from TG values (by dividing TG by 2.18) and lipoprotein was measured by a nephelometric assay performed on a Siemens BN II Nephelometer. hs-CRP, homocysteine, and CoQ10 were measured at weeks 0, 4, 8,12 , and 16. hsCRP was analyzed using a Dade Behring BNII nephelometer and homocysteine analyzed using FPIA technology (Gamma-Dynacare Medical Laboratories). Total CoQ10 analysis was performed by HPLC with UV detection by KGK Synergize Laboratory (London, ON, Canada). The HPLC method was adapted from Mosca et al. ${ }^{36}$

Adverse events (AE) were recorded, by the participants, in diaries and were monitored by the investigator from the time they had at least one dose of study product until the end of the treatment period. Unfavorable signs and symptoms, including any abnormal laboratory findings, disease, or the worsening of any preexisting conditions that were temporally associated with the use of the investigational product, were considered AEs. The study investigator assessed AEs and designated the causality relationship with the investigational product as most probable, probable, possible, unlikely, or unrelated.

\section{Statistical analyses}

Between-group analyses of demographic and baseline characteristics were performed using a covariate adjustment for a comparison of study end points, and where baseline values were missing, the values obtained from the screening visit were used.

Between-group analyses of primary and secondary end points and safety parameters were adjusted for baseline, and groups compared using an unpaired $t$-test. The Anderson-Darling test was used to determine whether data were non-normally distributed. Where data was non-normally distributed, between-group comparisons were made using a nonparametric test. Within-group comparisons were made using Student's $t$-test or Wilcoxon signed-ranks test, as appropriate. The "last value carried forward" technique was also applied where data was missing subsequent to week 2 , using the last available postrandomization observation for statistical analyses.

A between-group analysis of the proportion of participants experiencing adverse events was performed using the Fisher's exact test. All statistical analyses were performed using $R$, and probability values $<0.05$ were considered statistically significant.

\section{Results}

The participants enrolled in this study were predominantly white females; however, there was no statistically significant difference between groups at baseline (Table 1). A total of 32 participants completed the 4-week TLC diet lead-in and were randomized in a 1:1 ratio to receive either pantethine or placebo. Finally, 24 participants completed the 16-week supplementation (Figure 1).

\section{Lipid profile}

There was a reduction in plasma LDL-C, TC, and nonHDL-C levels in all participants during the 4-week TLC diet lead-in from screening to baseline (Figure 2). The participants on pantethine demonstrated a significant decrease in TC at week $16(P=0.040)$ and LDL-C at weeks 8 and 16 ( $P=0.020$ and $P=0.006$, respectively) compared with placebo. Non-HDL-C showed decreasing trends at week 8 $(P=0.102)$ and week $12(P=0.145)$, with values reaching significance by week $16(P=0.042)$, in the pantethine group compared with placebo. Homocysteine levels for

Table I Baseline physical characteristics of participants in the pantethine and placebo groups

\begin{tabular}{llll}
\hline Characteristic & $\begin{array}{l}\text { Pantethine } \\
(\mathbf{n}=16) \\
\text { mean } \pm \text { SD }\end{array}$ & $\begin{array}{l}\text { Placebo } \\
(\mathbf{n}=16) \\
\text { mean } \pm \text { SD }\end{array}$ & P-value $^{\mathbf{a}}$ \\
\hline Age (years) & $54.4 \pm 7.3$ & $47.2 \pm 12.1$ & 0.051 \\
$\begin{array}{l}\text { Height (cm) } \\
\text { Sex (\%) }\end{array}$ & $164.8 \pm 6.9$ & $169.3 \pm 7.5$ & 0.083 \\
$\quad$ Female & 87.50 & 56.25 & 0.113 \\
$\quad$ Male & 12.50 & 43.75 & \\
Race (\%) & & & \\
White & 87.50 & 93.75 & $>0.999$ \\
Other & 12.50 & 6.25 & $>0.999$ \\
\hline
\end{tabular}

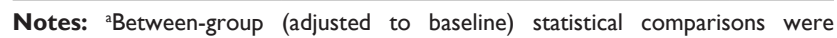
conducted using unpaired $t$-test. Probability values $P<0.05$ are significant. Abbreviation: SD, standard deviation. 
Pantethine $300 \mathrm{mg}$ tablet $\square$ Placebo tablet
Screen visit, $n=223$

4-week TLC diet lead, $n=32$

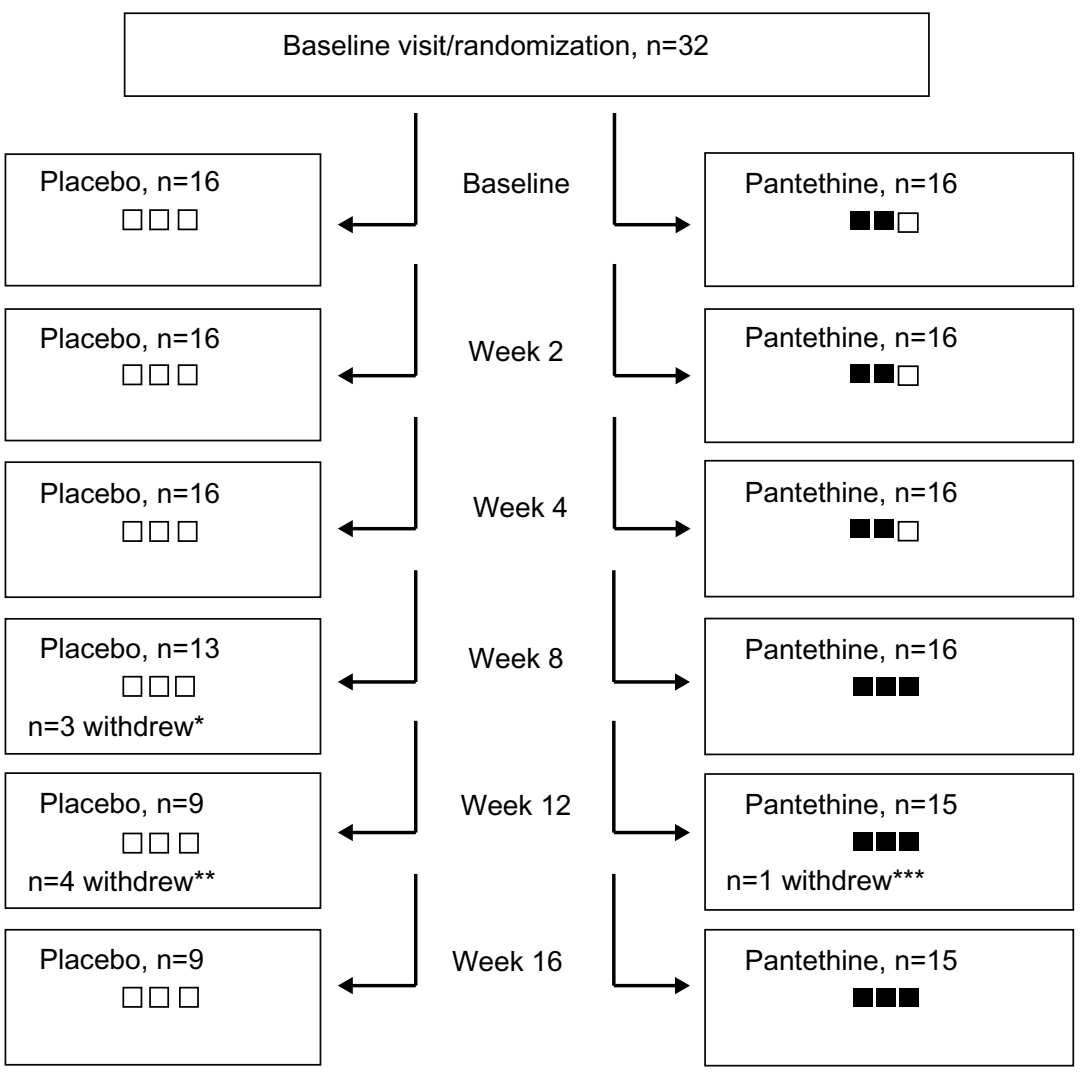

Figure I Subject disposition.

Notes: *Two subjects withdrew from the study due to adverse events, and one moved out of the city. The adverse events that were reported were: cold symptoms ( $\mathrm{n}=\mathrm{l}$ ); and presence of blood in the stool $(n=I)$. **Four subjects withdrew from the study due to adverse events. The adverse events that were reported were: LDL-C increased to ATP III high-risk category $(n=3)$; and one subject did not wish to continue study after being ill with strep throat $(n=1)$. ***One subject withdrew from the study due to an increase in LDL-C to ATP III high-risk category. The black boxes represent the pantethine tablets which was the investigational product and the white boxes represent the placebo. In order to maintain blinding all subjects received 3 tablets. At week 8 the dose was increased in the pantethine group so they received three pantethine tablets (three black boxes).

Abbreviations: ATP III, Adult Treatment Panel III (Expert Panel on Detection, Evaluation, and Treatment of High Blood Cholesterol in Adults); LDL-C, low-density lipoprotein cholesterol; TLC, Therapeutic Lifestyle Change.

both groups did not change significantly from baseline to week 16 .

Within groups, all participants demonstrated an insignificant decrease in their lipid profile from screening to baseline, during the 4-week lead-in TLC diet period. At week 4, a $6 \%$ decrease in TC $(P=0.005), 11 \%$ decrease in LDL-C $(P=0.002), 7 \%$ decrease in non-HDL-C $(P=0.005)$, and $4 \%$ decrease in Apo-B $(P=0.041)$ from baseline was seen in the pantethine group. These decreases continued to week 8 , week 12 , and week 16 for TC $(6 \%[P=0.007], 7 \%$ [ $P=0.031]$, and $6 \%[P=0.041]$, respectively), LDL-C $(11 \%[P<0.001]$, $11 \%$ [ $P=0.012]$, and $11 \%$ [ $P=0.004]$, respectively), and non-HDL-C $(8 \%$ [ $P=0.002], 9 \%[P=0.022]$, and $8 \%$ $[P=0.035]$, respectively). Improvements in LDL-C reached between-group significance at weeks $8(P=0.027)$ and 16 $(P=0.010)$. The within-group decrease in Apo-B showed a trend towards significance at week $8(5 \%[P=0.106])$ and decreased by $8 \%$ at week 12 , reaching significance $(P=0.032)$. The within-group decrease in the ratio of TC to HDL-C and non-HDL-C to HDL-C reached significance at week 8 (8\% $[P=0.004]$ and $9 \%[P=0.010]$, respectively) and week $12(7 \%[P=0.028]$ and $9 \%[P=0.030]$, respectively). The participants on placebo showed a $2 \%$ decrease in LDL-C concentrations at week 8 and a 3\% increase by week 16; however, these changes did not reach significance. There were no significant within-group changes, during the study period, in HDL-C, TG, VLDL-C, or lipoprotein(a) levels in the participants on pantethine. 
A

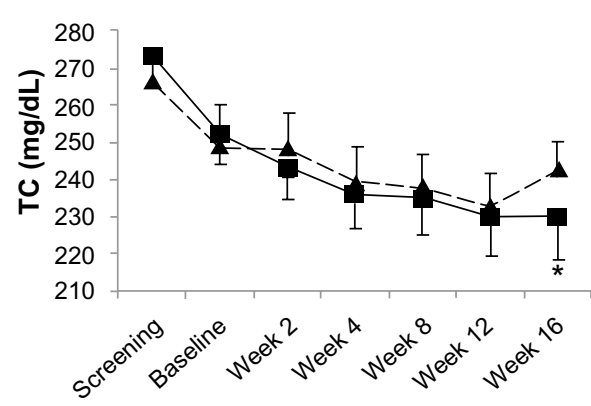

C

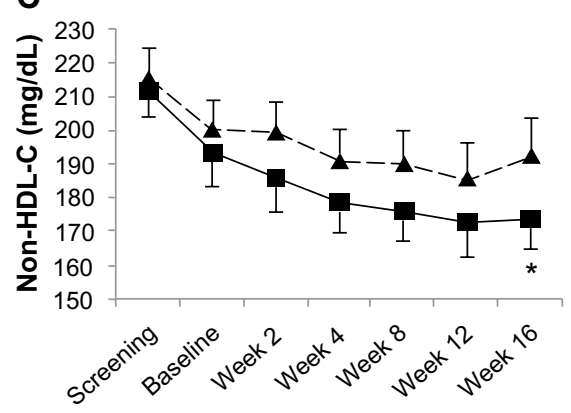

B

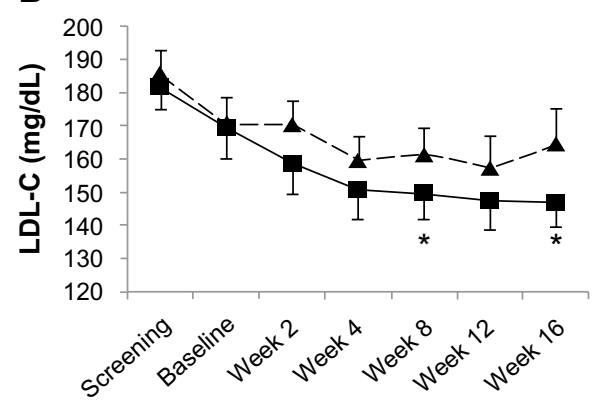

D

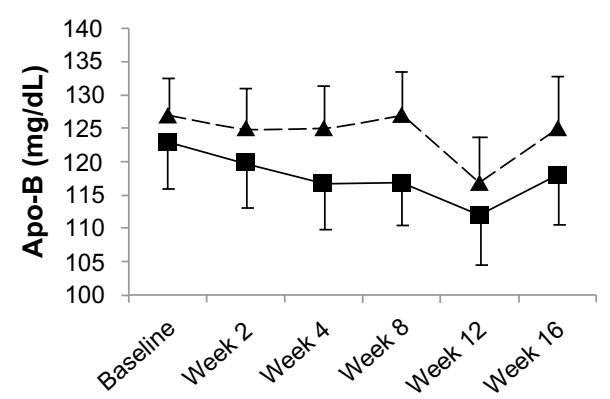

Figure 2 Changes in the serum (A) TC, (B) LDL-C, (C) non-HDL-C, and (D) Apo-B levels at screening, baseline, and weeks 2, 4, 8, I2 and I6 of the study period. Notes: Data are represented as the mean \pm SEM. Triangle $(\mathbf{\Delta})$ represents placebo, and square $(\mathbf{\square})$ represents pantethine. Asterisk $(*)$ indicates a statistically significant $(P<0.05)$ between-group statistical comparison, using baseline as a covariate.

Abbreviations: Apo-B, apolipoprotein B; LDL-C, low-density lipoprotein cholesterol; Non-HDL-C, non-high-density lipoprotein cholesterol; SEM, standard error of the mean; TC, total cholesterol.

A subgroup analysis based on sex revealed that females supplemented with pantethine had significantly lower percent TC at weeks $4(7 \%[P=0.003]), 8(8 \%[P=0.001]), 12(9 \%$ $[P=0.012])$, and $16(8 \%[P=0.010])$ compared with baseline. The within-group difference at week 16 translated into an $8 \%$ decrease in TC compared with those on placebo $(P=0.021)$. Females showed a significant decrease in LDL-C at weeks 4 $(P<0.001), 8(P<0.001), 12(P<0.006)$, and $16(P<0.001)$ compared with baseline. These changes resulted in a significant $12 \%$ decrease of LDL-C at week $8(P=0.016)$ and a $13 \%$ decrease at week $16(P=0.003)$ compared with placebo. Significant within-group changes in non-HDL-C were also seen in females at weeks $4,8,12$, and 16 . These changes were significantly better than placebo at week $16(P=0.018)$, showing an $11 \%$ decrease in non-HDL-C in the females on pantethine. The males on pantethine showed greater within-group decreases in LDL-C at weeks 2 and 4, but these changes did not reach significance between groups.

\section{Anthropomorphic parameters and blood chemistry}

There were no between- or within-group statistical differences in blood pressure, heart rate, waist circumference, or body mass index (BMI) during the study. The biochemistry and clinical chemistry of the participants showed there were no clinically relevant differences between the participants in the two groups (Table 2). CoQ10 increased from baseline to weeks 4, 8, 12, and 16 in participants on pantethine $(P=0.028, P=0.001, P=0.008$, and $P=0.001$, respectively) and placebo $(P=0.019, P=0.012$, $P=0.042$, and $P=0.027$, respectively); however, these increases were not statistically significant between groups (Table 2 ).

\section{Adverse events}

In the current study, a total of one symptom potentially attributed to study medication was recorded in one participant in the placebo group. A total of two symptoms (diarrhea and flatulence) potentially attributed to the study medication were reported by participants on pantethine. The diarrhea was moderate in intensity, experienced for 3 days during the $600 \mathrm{mg} /$ day dosage period, and did not recur when the dosage was escalated. The flatulence reported by one participant was experienced during both dosage periods, was mild in intensity, and resolved prior to the end of the study. A single mild episode of neutropenia was found in a participant on placebo.

\section{Discussion}

It is well established that elevated levels of plasma lipids play a major role in the development and progression of atherosclerotic disease. ${ }^{37-39}$ Lowering LDL-C levels in an individual reduces the CVD risk and incidence of 
Table 2 Biochemistry and clinical characteristics of participants in the pantethine and placebo groups

\begin{tabular}{|c|c|c|c|}
\hline & Pantethine & Placebo & $P$-value \\
\hline & (n) mean $\pm S D$ & (n) mean $\pm S D$ & \\
\hline \multicolumn{4}{|l|}{ Hemoglobin $(\mathrm{g} / \mathrm{L})$} \\
\hline Screening & (16) $139.90 \pm 5.90$ & (I6) $144.60 \pm 13.30$ & - \\
\hline Baseline & (I6) $138.40 \pm 6.10$ & (I6) $\mid 40.90 \pm I I .30$ & 0.508 \\
\hline Week 2 & (16) $138.40 \pm 7.20$ & (16) $141.90 \pm 12.20$ & 0.339 \\
\hline Week 4 & (I6) $137.10 \pm 8.30$ & (I6) $141.60 \pm 10.70$ & 0.201 \\
\hline $\begin{array}{l}\text { Week } 8 \text { dose } \\
\text { escalation }\end{array}$ & (I6) $136.50 \pm 9.50$ & (I3) $141.20 \pm 12.70$ & 0.260 \\
\hline Week 12 & (I5) $135.50 \pm 9.30$ & (9) $141.00 \pm 13.60$ & 0.253 \\
\hline $\begin{array}{l}\text { Week } 16 \text { end } \\
\text { of study }\end{array}$ & (I5) $134.60 \pm 8.20$ & (9) $142.20 \pm 13.00$ & 0.090 \\
\hline \multicolumn{4}{|l|}{ Hematocrit (L/L) } \\
\hline Screening & (I6) $0.408 \pm 0.020$ & (16) $0.422 \pm 0.039$ & - \\
\hline Baseline & (I6) $0.406 \pm 0.023$ & (16) $0.415 \pm 0.036$ & 0.412 \\
\hline Week 2 & (I6) $0.406 \pm 0.027$ & (16) $0.414 \pm 0.032$ & 0.444 \\
\hline Week 4 & (I6) $0.403 \pm 0.028$ & (16) $0.414 \pm 0.031$ & 0.289 \\
\hline $\begin{array}{l}\text { Week } 8 \text { dose } \\
\text { escalation }\end{array}$ & (I6) $0.402 \pm 0.032$ & (I3) $0.414 \pm 0.036$ & 0.357 \\
\hline Week 12 & (I5) $0.400 \pm 0.04 \mathrm{I}$ & (9) $0.4 \mathrm{I} 4 \pm 0.044$ & 0.428 \\
\hline $\begin{array}{l}\text { Week } 16 \text { end } \\
\text { of study }\end{array}$ & (I5) $0.402 \pm 0.039$ & (9) $0.424 \pm 0.039$ & 0.184 \\
\hline \multicolumn{4}{|c|}{ White blood cells (109/L) } \\
\hline Screening & (16) $6.19 \pm 1.52$ & (16) $7.14 \pm 2.31$ & - \\
\hline Baseline & (I6) $5.86 \pm 1.10$ & (I6) $6.46 \pm 1.85$ & 0.273 \\
\hline Week 2 & (I6) $5.96 \pm 1.33$ & (I6) $6.29 \pm 2.30$ & 0.821 \\
\hline Week 4 & (I6) $6.02 \pm 0.89$ & (I6) $6.5 \mathrm{I} \pm 2.27$ & 0.533 \\
\hline $\begin{array}{l}\text { Week } 8 \text { dose } \\
\text { escalation }\end{array}$ & (16) $5.83 \pm 1.19$ & (I3) $6.54 \pm 1.84$ & 0.218 \\
\hline Week 12 & (I5) $5.68 \pm I .48$ & (9) $5.87 \pm 2.37$ & 0.530 \\
\hline $\begin{array}{l}\text { Week } 16 \text { end } \\
\text { of study }\end{array}$ & (I5) $5.89 \pm 1.58$ & (9) $6.10 \pm 2.08$ & 0.835 \\
\hline \multicolumn{4}{|c|}{ Red blood cells $\left(10^{12} / \mathrm{L}\right)$} \\
\hline Screening & (I6) $4.52 \pm 0.28$ & (I6) $4.70 \pm 0.47$ & - \\
\hline Baseline & (I6) $4.45 \pm 0.23$ & (I6) $4.6 \mathrm{I} \pm 0.38$ & 0.173 \\
\hline Week 2 & (I6) $4.46 \pm 0.31$ & (I6) $4.59 \pm 0.36$ & 0.293 \\
\hline Week 4 & (I6) $4.40 \pm 0.28$ & (I6) $4.59 \pm 0.35$ & 0.115 \\
\hline $\begin{array}{l}\text { Week } 8 \text { dose } \\
\text { escalation }\end{array}$ & (I6) $4.40 \pm 0.32$ & (I3) $4.57 \pm 0.36$ & 0.189 \\
\hline Week 12 & (I5) $4.37 \pm 0.37$ & (9) $4.63 \pm 0.32$ & 0.087 \\
\hline $\begin{array}{l}\text { Week } 16 \text { end } \\
\text { of study }\end{array}$ & (I5) $4.35 \pm 0.30$ & (9) $4.7 I \pm 0.30$ & $0.01 I^{*}$ \\
\hline \multicolumn{4}{|l|}{ MCV (fL) } \\
\hline Screening & (16) $90.50 \pm 2.70$ & (I6) $90.10 \pm 3.70$ & - \\
\hline Baseline & (16) $91.30 \pm 3.00$ & (I6) $89.90 \pm 3.40$ & 0.242 \\
\hline Week 2 & (16) $91.20 \pm 3.10$ & (I6) $90.10 \pm 3.80$ & 0.401 \\
\hline Week 4 & (16) $91.20 \pm 3.20$ & (16) $90.40 \pm 3.90$ & 0.525 \\
\hline $\begin{array}{l}\text { Week } 8 \text { dose } \\
\text { escalation }\end{array}$ & (16) $91.50 \pm 3.30$ & (I3) $90.80 \pm 4.60$ & 0.626 \\
\hline Week 12 & (15) $91.90 \pm 3.80$ & (9) $89.30 \pm 4.80$ & 0.162 \\
\hline $\begin{array}{l}\text { Week } 16 \text { end } \\
\text { of study }\end{array}$ & (I5) $92.00 \pm 4.50$ & (9) $90.00 \pm 5.30$ & 0.332 \\
\hline \multicolumn{4}{|l|}{$\mathrm{MCH}(\mathrm{pg})$} \\
\hline Screening & (16) $31.02 \pm 1.18$ & (I6) $30.76 \pm 1.67$ & - \\
\hline Baseline & (16) $31.14 \pm 1.16$ & (I6) $30.66 \pm \mathrm{I} .40$ & 0.292 \\
\hline Week 2 & (16) $31.07 \pm 1.15$ & (I6) $30.96 \pm 1.49$ & 0.813 \\
\hline
\end{tabular}

Table 2 (Continued)

\begin{tabular}{|c|c|c|c|}
\hline & Pantethine & Placebo & $P$-value \\
\hline & (n) mean $\pm S D$ & (n) mean $\pm S D$ & \\
\hline Week 4 & (16) $31.18 \pm 1.15$ & (16) $30.97 \pm 1.74$ & 0.687 \\
\hline $\begin{array}{l}\text { Week } 8 \text { dose } \\
\text { escalation }\end{array}$ & (I6) $31.07 \pm 1.25$ & (I3) $30.95 \pm 1.81$ & 0.831 \\
\hline Week 12 & (I5) $31.10 \pm 1.18$ & (9) $30.37 \pm 1.53$ & 0.199 \\
\hline $\begin{array}{l}\text { Week } 16 \text { end } \\
\text { of study }\end{array}$ & (15) $31.02 \pm 1.13$ & (9) $30.10 \pm 1.49$ & 0.100 \\
\hline \multicolumn{4}{|c|}{$\mathrm{MCH}$ concentration $(\mathrm{g} / \mathrm{L})$} \\
\hline Screening & (I6) $342.50 \pm 5.80$ & (16) $341.70 \pm 6.10$ & - \\
\hline Baseline & (I6) $341.30 \pm 8.60$ & (I6) $340.60 \pm 6.90$ & 0.570 \\
\hline Week 2 & (I6) $340.90 \pm 8.90$ & (I6) $343.40 \pm 7.60$ & 0.387 \\
\hline Week 4 & (I6) $341.80 \pm 6.60$ & (16) $342.00 \pm 8.10$ & 0.943 \\
\hline $\begin{array}{l}\text { Week } 8 \text { dose } \\
\text { escalation }\end{array}$ & (I6) $339.60 \pm 7.90$ & (I3) $341.00 \pm 8.90$ & 0.648 \\
\hline Week 12 & (I5) $339.10 \pm 15.20$ & (9) $341.00 \pm 14.30$ & 0.698 \\
\hline $\begin{array}{l}\text { Week } 16 \text { end } \\
\text { of study }\end{array}$ & (I5) $337.10 \pm 14.80$ & (9) $334.90 \pm 13.50$ & $0.61 \mathrm{I}$ \\
\hline \multicolumn{4}{|l|}{ RDW (\%) } \\
\hline Screening & (16) $13.55 \pm 0.75$ & (16) $13.59 \pm 0.97$ & - \\
\hline Baseline & (I6) $13.76 \pm 0.94$ & (16) $13.73 \pm 1.03$ & 0.663 \\
\hline Week 2 & (16) $13.82 \pm 0.85$ & (16) $13.81 \pm 1.06$ & 0.971 \\
\hline Week 4 & (16) $13.84 \pm 0.92$ & (16) $|3.86 \pm 1.1|$ & 0.945 \\
\hline $\begin{array}{l}\text { Week } 8 \text { dose } \\
\text { escalation }\end{array}$ & (16) $13.98 \pm 1.05$ & (13) $13.64 \pm 1.20$ & 0.262 \\
\hline Week 12 & (I5) $13.97 \pm 1.23$ & (9) $13.96 \pm 1.23$ & $>0.999$ \\
\hline $\begin{array}{l}\text { Week } 16 \text { end } \\
\text { of study }\end{array}$ & (I5) $14.09 \pm 1.16$ & (9) $14.08 \pm 1.36$ & 0.952 \\
\hline \multicolumn{4}{|c|}{ Platelet count $\left(10^{9} / \mathrm{L}\right)$} \\
\hline Screening & (I6) $302.00 \pm 66.00$ & (I6) $276.00 \pm 79.00$ & - \\
\hline Baseline & (I5) $285.00 \pm 59.00$ & (I6) $260.00 \pm 67.00$ & 0.287 \\
\hline Week 2 & (I6) $293.00 \pm 61.00$ & (I6) $262.00 \pm 78.00$ & 0.222 \\
\hline Week 4 & (I6) $284.00 \pm 68.00$ & (I6) $263.00 \pm 70.00$ & 0.346 \\
\hline $\begin{array}{l}\text { Week } 8 \text { dose } \\
\text { escalation }\end{array}$ & (I6) $282.00 \pm 68.00$ & (13) $273.00 \pm 81.00$ & 0.735 \\
\hline Week 12 & (I5) $272.00 \pm 62.00$ & (9) $247.00 \pm 79.00$ & 0.221 \\
\hline $\begin{array}{l}\text { Week } 16 \text { end } \\
\text { of study }\end{array}$ & (I5) $267.00 \pm 67.00$ & (9) $269.00 \pm 96.00$ & 0.907 \\
\hline \multicolumn{4}{|l|}{ MPV (fL) } \\
\hline Screening & $8.37 \pm 0.81$ & (16) $8.99 \pm 0.88$ & - \\
\hline Baseline & (I5) $8.57 \pm 1.10$ & (16) $9.04 \pm 0.91$ & 0.208 \\
\hline Week 2 & (I6) $8.49 \pm 0.83$ & (16) $9.14 \pm 0.77$ & $0.028 *$ \\
\hline Week 4 & (I6) $8.52 \pm 0.86$ & (16) $9.22 \pm 0.91$ & $0.032 *$ \\
\hline $\begin{array}{l}\text { Week } 8 \text { dose } \\
\text { escalation }\end{array}$ & (I6) $8.54 \pm 0.76$ & (I3) $9.05 \pm 0.65$ & 0.063 \\
\hline Week 12 & (I5) $8.63 \pm 0.93$ & (9) $8.97 \pm 0.43$ & 0.436 \\
\hline $\begin{array}{l}\text { Week } 16 \text { end } \\
\text { of study }\end{array}$ & (I5) $8.66 \pm 0.94$ & (9) $9.04 \pm 0.55$ & 0.353 \\
\hline \multicolumn{4}{|c|}{ Neutrophils (109/L) } \\
\hline Screening & (I6) $3.57 \pm 1.07$ & (I6) $4.62 \pm 1.93$ & - \\
\hline Baseline & (I6) $3.47 \pm 0.91$ & (16) $3.94 \pm 1.36$ & 0.257 \\
\hline Week 2 & (I6) $3.46 \pm 0.99$ & (16) $3.96 \pm 1.87$ & 0.706 \\
\hline Week 4 & (I6) $3.65 \pm 0.7 \mid$ & (I6) $4.14 \pm 1.75$ & 0.307 \\
\hline $\begin{array}{l}\text { Week } 8 \text { dose } \\
\text { escalation }\end{array}$ & (I6) $3.41 \pm 1.00$ & (13) $4.17 \pm 1.46$ & 0.106 \\
\hline Week 12 & (I5) $3.30 \pm I .36$ & (9) $3.58 \pm I .43$ & 0.676 \\
\hline $\begin{array}{l}\text { Week } 16 \text { end } \\
\text { of study }\end{array}$ & (14) $3.33 \pm 1.03$ & (9) $3.60 \pm 1.24$ & 0.567 \\
\hline
\end{tabular}


Table 2 (Continued)

\begin{tabular}{|c|c|c|c|}
\hline & Pantethine & Placebo & \multirow[t]{2}{*}{ P-value } \\
\hline & (n) mean \pm SD & (n) mean $\pm S D$ & \\
\hline \multicolumn{4}{|l|}{ Lymphocytes (10\%/L) } \\
\hline Screening & (16) $1.99 \pm 0.51$ & (I6) $1.90 \pm 0.51$ & - \\
\hline Baseline & 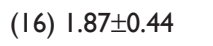 & (I6) $1.94 \pm 0.53$ & $0.7 \mid 4$ \\
\hline Week 2 & (16) $1.90 \pm 0.53$ & (I6) $1.73 \pm 0.47$ & 0.345 \\
\hline Week 4 & (I6) $1.79 \pm 0.40$ & (I6) $1.82 \pm 0.51$ & 0.878 \\
\hline $\begin{array}{l}\text { Week } 8 \text { dose } \\
\text { escalation }\end{array}$ & (I6) $1.86 \pm 0.39$ & (I3) $1.82 \pm 0.51$ & 0.817 \\
\hline Week 12 & (I5) I.79 \pm 0.63 & (9) $1.74 \pm 0.85$ & 0.474 \\
\hline $\begin{array}{l}\text { Week } 16 \text { end } \\
\text { of study }\end{array}$ & (I4) $2.07 \pm I .04$ & (9) $1.90 \pm 0.94$ & 0.378 \\
\hline \multicolumn{4}{|l|}{ Monocytes (109/L) } \\
\hline Screening & (I6) $0.40 \pm 0.14$ & (I6) $0.42 \pm 0.14$ & - \\
\hline Baseline & (I6) $0.34 \pm 0.13$ & (I6) $0.39 \pm 0.12$ & 0.350 \\
\hline Week 2 & (I6) $0.37 \pm 0.13$ & (I6) $0.39 \pm 0.11$ & 0.651 \\
\hline Week 4 & ( $0.38 \pm 0.09$ & (I6) $0.37 \pm 0.10$ & 0.816 \\
\hline $\begin{array}{l}\text { Week } 8 \text { dose } \\
\text { escalation }\end{array}$ & (I6) $0.35 \pm 0.12$ & (I3) $0.38 \pm 0.10$ & 0.507 \\
\hline Week 12 & (I5) $0.36 \pm 0.13$ & (9) $0.36 \pm 0.16$ & 0.591 \\
\hline $\begin{array}{l}\text { Week } 16 \text { end } \\
\text { of study }\end{array}$ & (I4) $0.38 \pm 0.12$ & (9) $0.33 \pm 0.14$ & 0.403 \\
\hline \multicolumn{4}{|l|}{ Eosinophils $\left(10^{9} / \mathrm{L}\right)$} \\
\hline Screening & (I6) $0.19 \pm 0.14$ & (I6) $0.16 \pm 0.12$ & - \\
\hline Baseline & (16) $0.15 \pm 0.10$ & (16) $0.15 \pm 0.14$ & 0.955 \\
\hline Week 2 & (I6) $0.19 \pm 0.12$ & (I6) $0.16 \pm 0.19$ & 0.375 \\
\hline Week 4 & (16) $0.18 \pm 0.13$ & (I6) $0.16 \pm 0.14$ & 0.748 \\
\hline $\begin{array}{l}\text { Week } 8 \text { dose } \\
\text { escalation }\end{array}$ & (16) $0.17 \pm 0.14$ & (I3) $0.16 \pm 0.12$ & 0.775 \\
\hline Week 12 & (I5) $0.22 \pm 0.19$ & (9) $0.17 \pm 0.19$ & 0.550 \\
\hline $\begin{array}{l}\text { Week } 16 \text { end } \\
\text { of study }\end{array}$ & (14) $0.17 \pm 0.13$ & (9) $0.22 \pm 0.17$ & 0.481 \\
\hline \multicolumn{4}{|l|}{ Basophils (10\%/L) } \\
\hline Screening & (I6) $0.050 \pm 0.028$ & (I6) $0.034 \pm 0.033$ & - \\
\hline Baseline & (I6) $0.04 I \pm 0.030$ & (I6) $0.028 \pm 0.038$ & 0.472 \\
\hline Week 2 & (I6) $0.049 \pm 0.032$ & (I6) $0.037 \pm 0.035$ & 0.157 \\
\hline Week 4 & (I6) $0.035 \pm 0.029$ & (I6) $0.04 \mathrm{I} \pm 0.036$ & 0.583 \\
\hline $\begin{array}{l}\text { Week } 8 \text { dose } \\
\text { escalation }\end{array}$ & (I6) $0.033 \pm 0.031$ & (I3) $0.032 \pm 0.034$ & 0.890 \\
\hline Week 12 & (I5) $0.023 \pm 0.026$ & (9) $0.026 \pm 0.025$ & 0.897 \\
\hline $\begin{array}{l}\text { Week } 16 \text { end } \\
\text { of study }\end{array}$ & (I4) $0.025 \pm 0.032$ & (9) $0.059 \pm 0.051$ & 0.090 \\
\hline \multicolumn{4}{|l|}{ Glucose (mmol/L) } \\
\hline Screening/baseline & 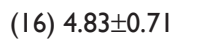 & (I6) $4.98 \pm 0.53$ & 0.677 \\
\hline \multicolumn{4}{|l|}{ Creatinine $(\mu \mathrm{mol} / \mathrm{L})$} \\
\hline Screening/baseline & (I6) $66.20 \pm 12.20$ & (I6) $75.90 \pm 15.00$ & 0.054 \\
\hline Week 16 end of study & (I6) $65.50 \pm 11.90$ & (I4) $74.50 \pm 13.00$ & 0.058 \\
\hline \multicolumn{4}{|l|}{ eGFR $\left(\mathrm{mL} / \mathrm{min} / \mathrm{I} .73 \mathrm{~m}^{2}\right)$} \\
\hline Screening/baseline & (I6) $84.90 \pm 7.20$ & (I6) $85.10 \pm 6.80$ & 0.787 \\
\hline $\begin{array}{l}\text { Week } 16 \text { end } \\
\text { of study }\end{array}$ & (I6) $85.80 \pm 6.90$ & (I4) $86.60 \pm 6.00$ & 0.588 \\
\hline
\end{tabular}

(Continued)
Table 2 (Continued)

\begin{tabular}{|c|c|c|c|}
\hline & Pantethine & Placebo & $P$-value \\
\hline & (n) mean $\pm S D$ & (n) mean $\pm S D$ & \\
\hline \multicolumn{4}{|l|}{ AST (U/L) } \\
\hline Screening & (I6) $20.50 \pm 6.20$ & (I6) $24.70 \pm 10.80$ & - \\
\hline Baseline & (16) $19.40 \pm 3.90$ & (16) $22.90 \pm 7.80$ & 0.198 \\
\hline Week 2 & (I6) $18.40 \pm 4.70$ & (16) $21.80 \pm 7.60$ & 0.142 \\
\hline Week 4 & (I6) $20.60 \pm 7.80$ & (I6) $24.40 \pm 12.60$ & 0.192 \\
\hline $\begin{array}{l}\text { Week } 8 \text { dose } \\
\text { escalation }\end{array}$ & (16) $19.20 \pm 4.30$ & (13) $23.20 \pm 9.80$ & 0.235 \\
\hline Week 12 & (I5) $17.80 \pm 3.90$ & (9) $22.70 \pm 7.70$ & $0.050 *$ \\
\hline $\begin{array}{l}\text { Week } 16 \text { end } \\
\text { of study }\end{array}$ & (I5) $18.90 \pm 5.60$ & (9) $25.20 \pm 8.10$ & $0.034^{*}$ \\
\hline \multicolumn{4}{|l|}{$\operatorname{ALT}(\mathrm{U} / \mathrm{L})$} \\
\hline Screening & (16) $19.50 \pm 9.90$ & (16) $33.10 \pm 31.90$ & - \\
\hline Baseline & (16) $18.00 \pm 7.60$ & (I6) $27.30 \pm 18.80$ & 0.131 \\
\hline Week 2 & (I6) $17.00 \pm 6.10$ & (I6) $26.10 \pm 17.70$ & 0.126 \\
\hline Week 4 & (16) $18.30 \pm 13.20$ & (I6) $27.10 \pm 21.70$ & 0.052 \\
\hline $\begin{array}{l}\text { Week } 8 \text { dose } \\
\text { escalation }\end{array}$ & (16) $16.50 \pm 7.30$ & (I3) $28.40 \pm 17.90$ & $0.014^{*}$ \\
\hline Week 12 & (I5) $16.10 \pm 5.80$ & (9) $29.30 \pm 17.10$ & $0.017^{*}$ \\
\hline $\begin{array}{l}\text { Week } 16 \text { end } \\
\text { of study }\end{array}$ & (I5) $17.70 \pm I I .50$ & (9) $35.30 \pm 22.10$ & $0.012 *$ \\
\hline \multicolumn{4}{|c|}{ Creatinine kinase (U/L) } \\
\hline Baseline & (16) $84.00 \pm 43.00$ & (16) $97.00 \pm 50.00$ & 0.346 \\
\hline $\begin{array}{l}\text { Week } 16 \text { end } \\
\text { of study }\end{array}$ & (16) $92.00 \pm 45.00$ & (I4) $86.00 \pm 42.00$ & 0.787 \\
\hline \multicolumn{4}{|l|}{ Homocysteine } \\
\hline Baseline & (16) $10.75 \pm 2.32$ & (I6) $10.31 \pm 2.77$ & 0.632 \\
\hline Week 4 & (16) $10.56 \pm 2.25$ & (16) $10.75 \pm 2.59$ & 0.829 \\
\hline $\begin{array}{l}\text { Week } 8 \text { dose } \\
\text { escalation }\end{array}$ & (I6) II. $25 \pm 2.27$ & (13) $9.85 \pm 2.30$ & 0.111 \\
\hline Week 12 & (I5) $10.67 \pm 1.95$ & (9) $8.56 \pm 3.8 \mathrm{I}$ & 0.085 \\
\hline $\begin{array}{l}\text { Week } 16 \text { end } \\
\text { of study }\end{array}$ & (I5) $10.20 \pm 1.66$ & (9) $9.78 \pm 2.05$ & 0.585 \\
\hline \multicolumn{4}{|l|}{ hs-CRP } \\
\hline Baseline & (I6) $1.65 \pm 1.6 \mathrm{I}$ & (I6) $3.5 \mathrm{I} \pm 3.44$ & $0.038 *$ \\
\hline Week 4 & (16) $1.69 \pm 1.58$ & (16) $3.47 \pm 3.33$ & $0.040 *$ \\
\hline $\begin{array}{l}\text { Week } 8 \text { dose } \\
\text { escalation }\end{array}$ & (I6) $1.87 \pm 1.72$ & (I3) $3.42 \pm 3.60$ & 0.227 \\
\hline Week 12 & (I5) $1.47 \pm 1.61$ & (9) $3.24 \pm 2.86$ & 0.073 \\
\hline $\begin{array}{l}\text { Week } 16 \text { end } \\
\text { of study }\end{array}$ & (I5) $1.48 \pm 1.59$ & (9) $3.27 \pm 2.64$ & $0.042 *$ \\
\hline \multicolumn{4}{|l|}{ CoQIO } \\
\hline Baseline & (16) $0.89 \pm 0.17$ & (16) $0.93 \pm 0.21$ & 0.895 \\
\hline Week 4 & (I6) $0.98 \pm 0.23$ & (I6) $1.03 \pm 0.28$ & 0.821 \\
\hline $\begin{array}{l}\text { Week } 8 \text { dose } \\
\text { escalation }\end{array}$ & (16) $1.08 \pm 0.27$ & (I3) $1.13 \pm 0.37$ & 0.948 \\
\hline Week 12 & (I5) $1.11 \pm 0.29$ & (9) $1.28 \pm 0.45$ & 0.551 \\
\hline $\begin{array}{l}\text { Week } 16 \text { end } \\
\text { of study }\end{array}$ & (I5) $1.15 \pm 0.32$ & (9) $1.32 \pm 0.45$ & 0.531 \\
\hline
\end{tabular}

Notes: Probability values $P<0.05$ are significant. $* P$-values that were significantly different between groups. The between group statistical significance in red blood cells, MPV and AST values remained within the normal laboratory reference range. Abbreviations: ALT, alanine transaminase; AST, aspartase aminotransferase; CoQI0, Coenzyme QI0; eGFR, estimated glomerular filtration rate; hs-CRP, high sensitivity $\mathrm{C}$-reactive protein; $\mathrm{MCH}$, mean corpuscular hemoglobin; $\mathrm{MCV}$, mean corpuscular volume; MPV, mean platelet volume; RDW, red cell distribution width; $\mathrm{SD}$, standard deviation. 
cardiovascular outcomes. ${ }^{4,40,41}$ Currently, cholesterol-lowering drugs, such as statins, lower LDL-C and the prevalence of cardiovascular events. ${ }^{6-8}$ However, intensive statin use has been associated with onset of diabetes, muscle and liver damage, and cognitive impairment. ${ }^{10-12,42}$

The ATP III recommends that the first line of treatment for a patient with abnormal LDL-C should be the TLC diet. Thereafter, individuals are categorized by risk factor profile and/or FRS and are considered to be eligible for statin therapy if LDL-C levels are above a specific goal. ${ }^{34}$ A previous study on pantethine investigated the efficacy of pantethine treatment in low-risk (FRS 10-year risk $<10 \%$ and LDL $<160 \mathrm{mg} / \mathrm{dL}$ ) or moderate-risk (FRS 10 -year risk $>10 \%$ but $<20 \%$ and LDL $<130 \mathrm{mg} / \mathrm{dL}$ ) subjects eligible for TLC diet initiation but not for statin therapy. In these participants, pantethine supplementation for 16 weeks significantly lowered TC and LDL-C over and above the TLC diet alone. ${ }^{34}$ The current study investigated the efficacy of pantethine on subjects eligible for statin therapy and therefore, with LDL-C levels above the ATP III goal for TLC diet changes (low FRS $[<10 \%$ per decade] or zero to one nonlipid risk factor, and LDL-C $>160 \mathrm{mg} / \mathrm{dL}$; or moderate FRS [ $>10$ but $<20 \%$ per decade] or two or fewer nonlipid risk factors, and LDL-C >130 mg/ dL). The results of our study confirmed the hypothesis that pantethine would significantly improve cholesterol metabolism, by lowering TC and LDL-C, without causing serious AEs in low- and moderate-CVD risk individuals eligible for statin therapy. Pantethine did not have an effect on TG levels, possibly because the enrolled participants had normal TG levels at baseline. The primary conclusion of this investigation is that the TLC diet alone did not produce a significant change in the lipid profile, but pantethine coupled with the TLC diet significantly decreased TC and LDL-C in participants during the 16-week study.

The Framingham Offspring Study has suggested a sex effect on LDL-C. ${ }^{43}$ The pantethine group had a higher female to male ratio than did the placebo group. A subgroup analysis on sex showed that there was no significant difference in LDL-C at screening or after the 4-week TLC diet lead-in, with participants in both groups having similar LDL-C values at baseline. However after the initiation of the supplementation, the pantethine group showed greater within-group decreases in LDL-C, reaching $11 \%$ by week 4 . The female participants showed a $13 \%$ decrease by week 8 , which was then maintained at weeks 12 and 16 . These within-group percentage changes were significant between groups at week 8 and week 16 , suggesting that the improvements in LDL-C in females were associated with pantethine supplementation. The Apo-B levels in the females on pantethine also showed significant decreases from baseline at weeks 2, 4, 8, 12, and 16; those on placebo showed an increase in Apo-B during the study. The male participants on pantethine did not show differences in lipid parameters, possibly due to the smaller sample numbers.

The increase from $600 \mathrm{mg} /$ day in weeks 1 through 8 to $900 \mathrm{mg} /$ day in weeks 9 through 16 did not appear to provide any additional or measurable benefit with respect to improvement in lipid parameters at week 12; however, significant improvements were observed by week 16 . These results suggest that the optimal benefit in low to moderate risk participants eligible for statin therapy is achieved at a $300 \mathrm{mg}$ twice per day dose schedule; however, levels of pantethine in the blood were not measured during the treatment period. According to the NCEP ATP-III, the initial LDL-C levels of the randomized participants in this trial were in the high category. At 16 weeks after randomization, the participants receiving placebo remained in the high category, while the participants receiving pantethine decreased to the borderline high category. The participants receiving pantethine demonstrated a reduction of LDL-C levels that reached $11 \%$ below baseline at week 16, a significant result compared with that of the participants on placebo, who showed a $3 \%$ increase. The length of this trial was a shortcoming of the study as after the 16 weeks of pantethine administration, the measured parameters had not plateaued, making prediction of the long-term outcome of pantethine on lipidemia difficult. Future clinical trials investigating the long-term administration of pantethine may demonstrate an even more robust decline in LDL-C and TC levels. A small sample size and absence of sex stratification were also limitations of this study design. Prior clinical studies have reported that for every $1 \%$ reduction of LDL-C levels, an approximate $1 \%$ relative risk reduction of major CHD events is attained. ${ }^{44-52}$ Participants receiving pantethine also had a $6 \%$ decrease in TC and $8 \%$ decrease in non-HDL-C, which was significantly different from participants on placebo who only had $2 \%$ and $1 \%$ decreases, respectively. Further evidence in the literature has demonstrated conclusively that lowering serum cholesterol concentration results in substantial protection from ischemic heart disease. . $^{3,40,53}$

There were no significant changes in homocysteine levels from baseline to week 16 and levels remained within the normal range $(\leq 15 \mu \mathrm{mol} / \mathrm{L})$ for both groups during this study. The effect of homocysteine on CVD risk remains uncertain. Homocysteine level is a prognostic marker of mortality and CVD events in patients with preexisting CVD risk factors. ${ }^{54}$ 
On the other hand, meta-studies have shown that reducing homocysteine levels by vitamin supplementation did not reduce the risk of major cardiovascular events or overall mortality in patients with vascular disease. ${ }^{55,56}$ As the mechanisms of action of pantethine in lowering cholesterol levels are not fully understood, it was important to consider the impact of pantethine supplementation, if any, on homocysteine.

The adverse events attributed to the study product were $6.3 \%$ for placebo and $12.5 \%$ for pantethine. In the placebo group, an unresolved mild blood and bone marrow AE (neutropenia) was observed. In the pantethine group, flatulence and diarrhea were reported, but these two events resolved during the study. The AEs reported in this study were consistent with the previously reported AEs of pantethine. ${ }^{32,34}$ Previous clinical studies have demonstrated that pantethine is well tolerated, with a low occurrence of side effects at dosages from 600 to $1,200 \mathrm{mg} /$ day. ${ }^{32,34}$

Some of the health risks of prolonged use of statins at high dosages include myalgias and increased risk of developing diabetes mellitus. These are related to concomitant lowering of in vivo $\mathrm{CoQ}_{10}$ production. Though not significant between groups, $\mathrm{CoQ}_{10}$ levels significantly increased from baseline to week 4 and remained increased at week 16 in both the pantethine and placebo group. It is possible that the TLC diet may have provided foods containing higher levels of $\mathrm{CoQ}_{10}$ compared with the meals the participants were consuming prior to the start of the study. Furthermore, plasma $\mathrm{CoQ}_{10}$ levels are not necessarily a reflection of tissue $\mathrm{CoQ}_{10}$ levels. ${ }^{57}$ Unlike statins, which are HMG-CoA reductase inhibitors that block the biosynthesis of $\mathrm{CoQ}_{10}$, pantethine did not block $\mathrm{CoQ}_{10}{ }^{58}$ Since pantethine does not affect $\mathrm{CoQ}_{10}$ production, the combined use of pantethine and a low dose of statins may act synergistically to lower LDL-C while minimizing the adverse effects related to a high dose of statins. Further research is required to test this hypothesis.

The mechanism of action of pantethine in its role as a lipid-lowering agent is yet to be clarified. It has been postulated that pantethine acts by inhibiting the enzymes acetyl-CoA carboxylase and $\mathrm{HMG}-\mathrm{CoA}$ reductase, thus modifying lipoprotein metabolism. ${ }^{22,34}$ Others have reported that neuropeptides activated by pantethine have an effect on calcitonin gene-related peptide (CGRP) and vasoactive intestinal polypeptide (VIP). ${ }^{53}$ Further research is required to determine whether the enhancement of blood flow and gut motility by both CGRP and VIP may be associated with improvements in the CVD end points measured in this study. ${ }^{54,55}$ Recently, gut microbiota and microbial metabolome have been identified to play important roles in CVD, diabetes, and cancer. ${ }^{59,60}$ Evidence from repeated randomized clinical studies have shown that probiotic bacterial strains, such Lactobacillus and Bifidobacterium, aid in decreasing lipids in hyperlipidemic adults. ${ }^{61,62}$ Pantethine has been reported to promote the survival and growth of various beneficial gut microorganisms. ${ }^{62-65}$ In vitro studies have identified a role for pantethine as a growth factor for Lactobacillus bulgaricus and Bifidobacterium bifidum, in promoting their survival and growth. ${ }^{64,65}$ These results, together with results of the human studies on pantethine, suggest the possible linkage of multiple mechanisms of actions in the various health benefits of pantethine.

\section{Conclusion}

This study confirms that pantethine lowers CVD risk markers in low to moderate CVD risk participants who are candidates for statins according to the NCEP guidelines. Compared with placebo, pantethine-treated participants demonstrated significant declines in LDL-C, HDL-C, and TC levels after 16 weeks of treatment. Moreover, unlike statins, which deplete $\mathrm{CoQ}_{10}$ to detrimental levels, both the pantethine and placebo groups significantly increased their $\mathrm{CoQ}_{10}$ levels above baseline. This study demonstrated that the TLC diet alone did not significantly affect lipid profiles but in conjunction with pantethine supplementation, significantly decreased lipid levels. Supplementation with pantethine may therefore be considered as an optional adjunctive therapy for patients with low to moderate CVD risk.

\section{Acknowledgments}

The authors wish to thank the volunteers of this study for their willingness and diligence in complying with the protocol. Larry Stitt, Assistant Director of the Biostatistical Unit, University of Western Ontario is thanked for his input on the statistical design and analysis. We acknowledge Sonya Barr for the conduct of the study, Josh Baisley for quality assurance and for his technical expertise, and Hui Jun Chew for reviewing and editing this manuscript. This study was supported by Daiichi Fine Chemical Co, Ltd.

\section{Disclosure}

JJN has received research funding or acted as a consultant to several nutraceutical and dietary supplement companies. IA is an employee of Daiichi Fine Chemical Co, Ltd. TK and DC are employees of Kyowa Hakko USA, Inc. The authors report no other conflicts of interest in this work. 


\section{References}

1. Wilson PWF, Ralph B. D’Agostino RB, Levy D, Belanger AM, Silbershatz H, Kannel WB. Prediction of Coronary Heart Disease Using Risk Factor Categories; Circulation. 1998,97:1837-1847.

2. Grundy SM, Cleeman JI, Merz CN, Brewer HB Jr, Clark LT, Hunninghake DB, Pasternak RC, Smith SC Jr, Stone NJ. Implications of recent clinical trials for the National Cholesterol Education Program Adult Treatment Panel III guidelines. Circulation 2004;110(2): 227-39.

3. Grundy SM, Cleeman JI, Merz CN, et al; Coordinating Committee of the National Cholesterol Education Program. Implications of recent clinical trials for the National Cholesterol Education Program Adult Treatment Panel III guidelines. Arterioscler Thromb Vasc Biol. 2004;24(8):e149-e161.

4. Expert Panel on Detection, Evaluation, and Treatment of High Blood Cholesterol in Adults. Executive summary of The Third Report of the National Cholesterol Education Program (NCEP) Expert Panel on Detection, Evaluation, and Treatment of High Blood Cholesterol In Adults (Adult Treatment Panel III). JAMA. 2001;285(19): 2486-2497.

5. Schober SE, Carroll MD, Lacher DA, Hirsch R; Division of Health and Nutrition Examination Surveys. High Serum Total Cholesterol - An Indicator for Monitoring Cholesterol Lowering Efforts: US Adults, 2005-2006. NCHS Data Brief. Hyattsville, MD: US Department of Health and Human Services; 2007.

6. Anand SS. Quantifying effect of statins on low density lipoprotein cholesterol, ischaemic heart disease, and stroke: systematic review and meta-analysis. Law MR, Wald NJ, Rudnicka AR. BMJ 2003;326 1407-408. Vasc Med. 2003;8(4):289-290.

7. Thavendiranathan P, Bagai A, Brookhart MA, Choudhry NK. Primary prevention of cardiovascular diseases with statin therapy: a meta-analysis of randomized controlled trials. Arch Intern Med. 2006;166(21):2307-2313.

8. Gotto AM. Treating hypercholesterolemia: looking forward. Clin Cardiol. 2003;26(1 Suppl 1):I21-I28.

9. Mann D, Reynolds K, Smith D, Muntner P. Trends in statin use and low-density lipoprotein cholesterol levels among US adults: impact of the 2001 National Cholesterol Education Program guidelines. Ann Pharmacother. 2008;42(9):1208-1215.

10. Preiss D, Seshasai SR, Welsh P, et al. Risk of incident diabetes with intensive-dose compared with moderate-dose statin therapy: a metaanalysis. JAMA. 2011;305(24):2556-2564.

11. Hodel C. Myopathy and rhabdomyolysis with lipid-lowering drugs. Toxicol Lett. 2002;128(1-3):159-168.

12. Davidson MH. Combination therapy for dyslipidemia: safety and regulatory considerations. Am J Cardiol. 2002;90(10B):50K-60K.

13. Culver AL, Ockene IS, Balasubramanian R, et al. Statin use and risk of diabetes mellitus in postmenopausal women in the Women's Health Initiative. Arch Intern Med. 2012;172(2):144-152.

14. Sattar N, Preiss D, Murray HM, et al. Statins and risk of incident diabetes: a collaborative meta-analysis of randomised statin trials. Lancet. 2010;375(9716):735-742.

15. Waters DD, Ho JE, DeMicco DA, et al. Predictors of new-onset diabetes in patients treated with atorvastatin: results from 3 large randomized clinical trials. J Am Coll Cardiol. 2011;57(14):1535-1545.

16. Rajpathak SN, Kumbhani DJ, Crandall J, Barzilai N, Alderman M, Ridker PM. Statin therapy and risk of developing type 2 diabetes: a meta-analysis. Diabetes Care. 2009;32(10):1924-1929.

17. Sabatine MS, Wiviott SD, Morrow DA, McCabe CH, Cannon CP. Highdose atorvastatin associated with worse glycemic control: a PROVE-IT TIMI 22 substudy. Circulation. 2004;110(Suppl III):S834.

18. Koh KK, Quon MJ, Han SH, Lee Y, Kim SJ, Shin EK. Atorvastatin causes insulin resistance and increases ambient glycemia in hypercholesterolemic patients. J Am Coll Cardiol. 2010;55(12):1209-1216.

19. Cighetti G, Del Puppo M, Paroni R, Galli Kienle M. Modulation of HMG-CoA reductase activity by pantetheine/pantethine. Biochim Biophys Acta. 1988;963(2):389-393.
20. Hsu JC, Tanaka K, Inayama I, Ohtani S. Effects of pantethine on lipogenesis and $\mathrm{CO} 2$ production in the isolated hepatocytes of the chick (Gallus domesticus). Comp Biochem Physiol Comp Physiol. 1992;102(3):569-572.

21. Wittwer CT, Gahl WA, Butler JD, Zatz M, Thoene JG. Metabolism of pantethine in cystinosis. J Clin Invest. 1985;76(4):1665-1672.

22. Branca D, Scutari G, Siliprandi N. Pantethine and pantothenate effect on the CoA content of rat liver. Int J Vitam Nutr Res. 1984;54(2-3): 211-216.

23. Prisco D, Rogasi PG, Matucci M, et al. Effect of oral treatment with pantethine on platelet and plasma phospholipids in IIa hyperlipoproteinemia. Angiology. 1987;38(3):241-247.

24. Gensini GF, Prisco D, Rogasi PG, Matucci M, Neri Serneri GG Changes in fatty acid composition of the single platelet phospholipids induced by pantethine treatment. Int J Clin Pharmacol Res. 1985;5(5):309-318.

25. Guthikonda S, Haynes WG. Homocysteine: role and implications in atherosclerosis. Curr Atheroscler Rep. 2006;8(2):100-106.

26. Miller AL, Kelly GS. homocysteine metabolism: nutritional modulation and impact on health and disease. Altern Med Rev. 1997;2(4): 234-254.

27. Arsenio L, Bodria P, Magnati G, Strata A, Trovato R. Effectiveness of long-term treatment with pantethine in patients with dyslipidemia. Clin Ther. 1986;8(5):537-545.

28. Gaddi A, Descovich GC, Noseda G, et al. Controlled evaluation of pantethine, a natural hypolipidemic compound, in patients with different forms of hyperlipoproteinemia. Atherosclerosis. 1984;50(1): 73-83.

29. Carrara P, Matturri L, Galbussera M, Lovati MR, Franceschini G, Sirtori CR. Pantethine reduces plasma cholesterol and the severity of arterial lesions in experimental hypercholesterolemic rabbits. Atherosclerosis. 1984;53(3):255-264.

30. Bertolini S, Donati C, Elicio N, et al. Lipoprotein changes induced by pantethine in hyperlipoproteinemic patients: adults and children. Int $J$ Clin Pharmacol Ther Toxicol. 1986;24(11):630-637.

31. Murai A, Miyahara T, Tanaka T, Sako Y, Nishimura N, Kameyama M. The effects of pantethine on lipid and lipoprotein abnormalities in survivors of cerebral infarction. Artery. 1985;12(4):234-243.

32. McRae MP. Treatment of hyperlipoproteinemia with pantethine: a review and analysis of efficacy and tolerability. Nutr Res. 2005;25(4): 319-333.

33. Coronel F, Tornero F, Torrente J, et al. Treatment of hyperlipemia in diabetic patients on dialysis with a physiological substance. Am J Nephrol. 1991;11(1):32-36.

34. Rumberger JA, Napolitano J, Azumano I, Kamiya T, Evans M. Pantethine, a derivative of vitamin $\mathrm{B}(5)$ used as a nutritional supplement, favorably alters low-density lipoprotein cholesterol metabolism in low- to moderate-cardiovascular risk North American subjects: a triple-blinded placebo and diet-controlled investigation. Nutr Res. 2011;31(8):608-615.

35. Yuhasz M.S., Physical Fitness Manual. University of Western Ontario, London, Canada. 1997.

36. Mosca F.; Fattorini D.; Bompadre S.; Littarru G.P. Assay of Coenzyme Q10 in Plasma by a Single Dilution Step. Anal Biochem. 305(2002)49-54.

37. Pyörälä K, De Backer G, Graham I, Poole-Wilson P, Wood D. Prevention of coronary heart disease in clinical practice. Recommendations of the Task Force of the European Society of Cardiology, European Atherosclerosis Society and European Society of Hypertension. Eur Heart J. 1994;15(10):1300-1331.

38. Castelli WP, Anderson K, Wilson PW, Levy D. Lipids and risk of coronary heart disease. The Framingham Study. Ann Epidemiol. 1992;2(1-2):23-28.

39. Verschuren WM, Jacobs DR, Bloemberg BP, et al. Serum total cholesterol and long-term coronary heart disease mortality in different cultures. Twenty-five-year follow-up of the seven countries study. JAMA. 1995;274(2):131-136. 
40. Buchwald H, Varco RL, Matts JP, et al. Effect of partial ileal bypass surgery on mortality and morbidity from coronary heart disease in patients with hypercholesterolemia. Report of the Program on the Surgical Control of the Hyperlipidemias (POSCH) . N Engl J Med. 1990;323(14):946-955.

41. O'Keefe JH, Cordain L, Harris WH, Moe RM, Vogel R. Optimal lowdensity lipoprotein is 50 to $70 \mathrm{mg} / \mathrm{dl}$ : lower is better and physiologically normal. J Am Coll Cardiol. 2004;43(11):2142-2146.

42. Golomb BA, Criqui MH, White H, Dimsdale JE. Conceptual foundations of the UCSD Statin Study: a randomized controlled trial assessing the impact of statins on cognition, behavior, and biochemistry. Arch Intern Med. 2004;164(2):153-162.

43. Schaefer EJ, Lamon-Fava S, Cohn SD, et al. Effects of age, gender, and menopausal status on plasma low density lipoprotein cholesterol and apolipoprotein B levels in the Framingham Offspring Study. J Lipid Res. 1994;35(5):779-792.

44. Heart Protection Study Collaborative Group. MRC/BHF Heart Protection Study of cholesterol lowering with simvastatin in 20,536 high-risk individuals: a randomised placebo-controlled trial. Lancet. 2002;360(9326):7-22.

45. Shepherd J, Blauw GJ, Murphy MB, et al; PROSPER study group. PROspective Study of Pravastatin in the Elderly at Risk. Pravastatin in elderly individuals at risk of vascular disease (PROSPER): a randomised controlled trial. Lancet. 2002;360(9346):1623-1630.

46. ALLHAT Officers and Coordinators for the ALLHAT Collaborative Research Group. The Antihypertensive and Lipid-Lowering Treatment to Prevent Heart Attack Trial. Major outcomes in moderately hypercholesterolemic, hypertensive patients randomized to pravastatin vs usual care: The Antihypertensive and Lipid-Lowering Treatment to Prevent Heart Attack Trial (ALLHAT-LLT). JAMA. 2002;288(23):2998-3007.

47. Sever PS, Dahlöf B, Poulter NR, et al; ASCOT investigators. Prevention of coronary and stroke events with atorvastatin in hypertensive patients who have average or lower-than-average cholesterol concentrations, in the Anglo-Scandinavian Cardiac Outcomes Trial - Lipid Lowering Arm (ASCOT-LLA): a multicentre randomised controlled trial. Lancet. 2003;361(9364):1149-1158.

48. Randomised trial of cholesterol lowering in 4444 patients with coronary heart disease: the Scandinavian Simvastatin Survival Study (4S). Lancet. 1994;344(8934):1383-1389.

49. Sacks FM, Pfeffer MA, Moye LA, et al. The effect of pravastatin on coronary events after myocardial infarction in patients with average cholesterol levels. Cholesterol and Recurrent Events Trial investigators. N Engl J Med. 1996;335(14):1001-1009.

50. Prevention of cardiovascular events and death with pravastatin in patients with coronary heart disease and a broad range of initial cholesterol levels. The Long-Term Intervention with Pravastatin in Ischaemic Disease (LIPID) Study Group. $N$ Engl J Med. 1998;339(19):1349-1357.

51. Shepherd J, Cobbe SM, Ford I, et al. Prevention of coronary heart disease with pravastatin in men with hypercholesterolemia. West of Scotland Coronary Prevention Study Group. N Engl J Med. 1995; 333(20):1301-1307.
52. Downs JR, Clearfield M, Weis S, et al. Primary prevention of acute coronary events with lovastatin in men and women with average cholesterol levels: results of AFCAPS/TexCAPS. Air Force/Texas Coronary Atherosclerosis Prevention Study. JAMA. 1998;279(20):1615-1622.

53. Law MR, Wald NJ, Thompson SG. By how much and how quickly does reduction in serum cholesterol concentration lower risk of ischaemic heart disease? BMJ. 1994;308(6925):367-372.

54. Refsum H, Nurk E, Smith AD, et al. The Hordaland Homocysteine Study: a community-based study of homocysteine, its determinants, and associations with disease. J Nutr. 2006;136(Suppl 6): 1731S-1740S.

55. Lonn E, Yusuf S, Arnold MJ, et al; Heart Outcomes Prevention Evaluation (HOPE) 2 Investigators. Homocysteine lowering with folic acid and B vitamins in vascular disease. $N$ Engl J Med. 2006;354(15): 1567-1577.

56. Clarke R, Halsey J, Lewington S, et al; B-Vitamin Treatment Trialists' Collaboration. Effects of lowering homocysteine levels with B vitamins on cardiovascular disease, cancer, and causespecific mortality: Meta-analysis of 8 randomized trials involving 37485 individuals. Arch Intern Med. 2010;170(18):1622-1631.

57. Molyneux SL, Young JM, Florkowski CM, Lever M, George PM. Coenzyme Q10: is there a clinical role and a case for measurement? Clin Biochem Rev. 2008;29(2):71-82.

58. Ghirlanda G, Oradei A, Manto A, et al. Evidence of plasma CoQ10lowering effect by HMG-CoA reductase inhibitors: a double-blind, placebo-controlled study. J Clin Pharmacol. 1993;33(3):226-229.

59. SanzY, Santacruz A, Gauffin P. Gut microbiota in obesity and metabolic disorders. Proc Nutr Soc. 2010;69(3):434-441.

60. Russell WR, Duncan SH, Flint HJ. The gut microbial metabolome: modulation of cancer risk in obese individuals. Proc Nutr Soc. 2013; 72(1):178-188

61. Jones ML, Tomaro-Duchesneau C, Martoni CJ, Prakash S. Cholesterol lowering with bile salt hydrolase-active probiotic bacteria, mechanism of action, clinical evidence, and future direction for heart health applications. Expert Opin Biol Ther. 2013;13(5):631-642.

62. Craig JA, Snell EE. The comparative activities of pantethine, pantothenic acid, and coenzyme A for various microorganisms. J Bacteriol. 1951;61(3):283-291.

63. Ueda M, Nakamoto S, Nakai R, Takagi A. Establishment of a defined minimal medium and isolation of auxotrophic mutants for Bifidobacterium Bifidium ES 5. J Gen Appl Microbiol. 1983;29:103-114.

64. György P, Rose C. Further observations on the metabolic requirements of Lactobacillus bifidus var. pennsylvanicus. J Bacteriol. 1955;69(5): 483-490.

65. Sultanbawa Y. Effects of bifidogenic factors on growth of Bifidobacterium bifidum in cultured milk yoghurt. $J$ Natn Sci Foundation Sri Lanka. 2006;34(4):205-209.
Vascular Health and Risk Management

\section{Publish your work in this journal}

Vascular Health and Risk Management is an international, peerreviewed journal of therapeutics and risk management, focusing on concise rapid reporting of clinical studies on the processes involved in the maintenance of vascular health; the monitoring, prevention and treatment of vascular disease and its sequelae; and the involvement of

\section{Dovepress}

metabolic disorders, particularly diabetes. This journal is indexed on PubMed Central and MedLine. The manuscript management system is completely online and includes a very quick and fair peer-review system, which is all easy to use. Visit http://www.dovepress.com/ testimonials.php to read real quotes from published authors. 